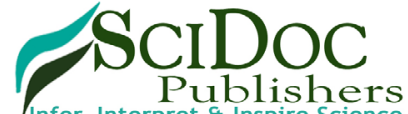

Publishers

ISSN:2326-3350

\title{
Assessment of the Acceptability and Palatability of Catfish (Clarias gariepinus) Preserved with Scent Leaf (Ocimum gratissimum) and Bitter Leaf (Vernonia amygdalina) Extracts
}

Research Article

RN Oladosu-Ajayi ${ }^{* *}$, HE Dienye ${ }^{2}$, SO Imoniaga ${ }^{1}$

${ }^{1}$ Department of Fisheries Technology, FCFFT, New Bussa, Niger State, Nigeria.

${ }^{2}$ Department of Fisheries. University of Portharcourt, Rivers State, Nigeria.

Abstract

The acceptability of catfish, Clarias gariepinus preserved with ethanolic extracts of scent leaf (Ocimum gratissimum) and bitter leaf (Vernonia amygdalina). The plants were divided into two portions, one portion was washed and the other unwashed before their extracts were made. The fish was prepared into smoked fish and pepper soup samples and a trained panel of judges was used to assess the acceptability make comments through a questionnaire. The results showed that the fish products preserved with unwashed bitter leaf extracts was more acceptable than its scent leaf counterpart (in terms of appearance and taste).

\section{Introduction}

Foods are usually classified as less perishable, moderately perishable and highly perishable in order to understand their perishable nature. Cereals, nuts and grains are included in less perishable and more stable category, vegetables as moderately perishable and sea foods as highly perishable food item [9]. Fish is a major source of food for humans and it contains minerals important for their diet as well as having the highest amino acid profile of essential sulphur-containing amino acids such as Methionine, lysine and cysteine [3]. Shelf life of fish can be described as the period of time which fish remain in optimum condition and suitable for consumption. Shelf life of a product is affected by a number of variables such as the intrinsic ( $\mathrm{pH}$ and moisture content) and extrinsic parameters (environmental factors) [2]. Acceptability is defined as the feature of experiences characterized by a positive attitude in preference or liking of a specified food item. Among several factors which determine the acceptability of food, palatability is the foremost. Palatability of food is the hedonic word provided by foods or fluids that are agreeable to the 'palate' in regard to the homeostatic satisfaction of nutritional, water or energy. The palatability of food or fluid unlike its flavour or taste varies with the state of an individual [5]. Scent leaf, (Ocimum gratissimum) are broad, narrow and ovate, usually $5-13 \mathrm{~cm}$ long and $3-9 \mathrm{~cm}$ wide.
It is extensively used in folk medicine throughout West Africa as a antimalaria and anticonvulsant. The crushed leaf juice is used in the treatment of convulsion, stomach pain and catarrh [4]. Phytochemical evaluation of scent leaf has shown that it is rich in alkaloid, tannin, phytates, flavonoids and oligosaccharides [6]. Bitter leaf, (Vernonia amygdalina) is a member of the genus that contains about 1000 species of forbs and shrubs in the family Asteraceae. Some species are known as iron weed while some are edible and of great economic value. Its common names among others include ewuro in Yoruba and onugbu in Ibo etc. Vernonia amygdalina is medicinal with several uses such as fever reduction, non-pharmaceutical solution to persistent fever headache and joint pain [7]. These various uses are the reasons why this present study hopes to compare the acceptability and palatability of fish preserved with scent leaf and bitter leaf extracts and to also suggest ways of improving the preserved products.

\section{Materials and Methods}

\section{Collection of Plant Materials}

The study site was located in the Federal College of Fresh water Fisheries Technology New Bussa in Niger State Fisheries laborartory. Fresh leaves of plant materials bitter leaf (Vernonia amygda-

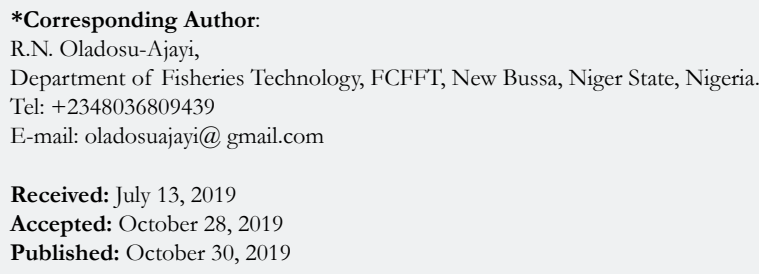


lina) and scent leaf (Ocimum gratissimum) were collected early in the morning from a home garden in Federal College of Fresh water Fisheries Technology New Bussa in Niger State. staff quarters. The leaves were cut from a non-flowered stalk and were identified at the herbarium of Fisheries College.

\section{Preparation of Bitter Leaf and Scent Leaf Extracts}

The bitter leaf (Vernonia amygdalina) and scent leaf (Ocimum gratissimum) were first separated from the stalk, rinsed with clean distilled water to remove the dust and dirts. It was divided into two portions one part of the leaf was unwashed and the other part was washed to remove oart of the juice that is responsible for the bitter taste. The extraction was done as follows according to Azu and Onyeagba (2007) [1].

1. $300 \mathrm{~g}$ of macerated bitter leaf was soaked in $150 \mathrm{ml}$ of $95 \%$ ethanol for 24 hours. The pulp obtained was left in a clean, sterile glass container and shaken vigorously to allow for proper extraction. Filtration was done using a sterile muslin cloth after which the extract obtained was air-dried and stored for use. This procedure was followed for both the washed and unwashed samples of the bitter leaf.

2. The scent leaf extracts were also prepared using the procedure in (1) above.

\section{Preparation of Fish Samples and Preservation Using Ex- tracts}

The catfish (Clarias gariepinus) samples were purchased from a farm in Power Holding Company of Nigeria (PHCN) Senior Staff quarters in New Bussa, Niger state. The fish were transported in kegs to the Fish Museum at Federal College of Freshwater Fisheries Technology (FCFFT), New Bussa, Niger State. The fish were cut to pieces, gutted and washed. These pieces were then dipped in the extracts (bitter leaf and scent leaf) separately for 10 minutes. These were then prepared into smoked fish and fresh fish pepper soup samples respectively.

\section{Acceptability and Palatability Study}

Subjective analysis was used for acceptability and palatability study. Ten members of the panel were selected for each parameter like flavour, texture, appearance and palatability trained on the rudimentary aspects of organoleptic characteristics and how to apportion mark to each parameter. of the smoked fish and fresh fish pepper soup samples preserved in scent leaf and bitter leaf extracts. The fish samples were given out with questionnaires for the panel members to taste the fish and score based on how the taste, texture, palatability and odour appealed to them. The questionnaires were returned and marks were appropriately ap- portioned to each parameter. according to the Poste et al., (1991) [8]. Test were replicated in triplicates for each treatment. The sensory evaluation of the prepared fish samples was classified according to the criteria in Table 1 below.

\section{Statistical Analysis}

Data obtained were subjected to analysis of variance (ANOVA) and where significant difference existed at 0.05 significant levels, treatment means were separated using Tukey's Test. Acceptance was calculated using:

Acceptance $(\%)=($ Score Obtained $/$ Score Obtainable $) \times 100$

\section{Results and Discussion}

The results of this work showed variation between the acceptability and palatability of samples of catfish preserved with extracts of washed and unwashed scent leaf and bitter leaf. Table 2 shows the acceptability of catfish (Clarias gariepinus) preserved with bitter leaf and scent leaf extracts that were prepared into pepper soup. Table 3 shows the acceptability of catfish (Clarias gariepinus) preserved with bitter leaf and scent leaf extracts that were smoked. Table 4 shows the palatability of catfish (Clarias gariepinus) preserved with bitter leaf and scent leaf extracts that were prepared into pepper soup. Table 5 shows the acceptability of catfish (Clarias gariepinus) preserved with bitter leaf and scent leaf extracts that were smoked.

Fish preservation is an important method of extending the shelf life of fish in order to improve the quality of the products. The results of this work showed the acceptability and palatability of fish preserved with ethanolic extracts of washed and unwashed bitter leaf and scent leaf. As was observed, the bitter leaf-preserved (washed and unwashed) samples (smoked and pepper soup) were more acceptable than the scent leaf-preserved samples. The bitter leaf extract (washed and unwashed) gave both the smoked fish and pepper soup a pronounced bitter taste that the pepper soup spices was unable to cover up and this made it more acceptable and presentable. Most of the members of the panel would go for it if placed on sale because of its flavour, appearance and bitter taste of both the smoked fish and the fresh fish pepper soup. Suggestions on how to improve the smoked fish products include increasing the concentration of the bitter leaf extract to increase the flavour of the smoked fish sample, avoid smoke contact with the fish, proper smoke drying of the fish and the use of moderate heat to improve the appearance. To improve the pepper soup, it was suggested that red pepper and salt could be added. The bitter leaf washing should also be limited as well as efforts to prepare the extracts in powdery form to make it more concentrated. The fish products preserved with ethanolic extracts of scent leaf

Table 1. Quality classification of treated fish based on sensory evaluation.

\begin{tabular}{|c|c|}
\hline Grade Score (\%) & Assessment Quality \\
\hline A $>70$ & Extremely liked \\
\hline B $60-69$ & Moderately liked \\
\hline C 50-59 & Liked \\
\hline D $40-49$ & Fair \\
\hline E $<40$ & Bad \\
\hline
\end{tabular}


Table 2. Acceptability of bitter leaf and scent leaf extracts preserved catfish (Clarias gariepinus) pepper soup.

\begin{tabular}{|c|c|c|c|c|}
\hline \multirow{2}{*}{ GRADE } & \multicolumn{2}{|c|}{ BITTER LEAF } & \multicolumn{2}{c|}{ SCENT LEAF } \\
\cline { 2 - 5 } & Unwashed (\%) & Washed (\%) & Unwashed (\%) & Washed (\%) \\
\hline Extremely liked & 57 & 43 & 42.9 & 28.59 \\
\hline Moderately liked & 43 & 57 & 14.28 & 14.28 \\
\hline Liked & - & - & 28.57 & 28.57 \\
\hline Fair & - & - & 14.25 & 14.28 \\
\hline Bad & - & - & - & 14.28 \\
\hline Total & 100 & 100 & 100 & 100 \\
\hline
\end{tabular}

Table 3. Acceptability of bitter leaf and scent leaf extracts preserved smoked catfish (Clarias gariepinus).

\begin{tabular}{|c|c|c|c|c|}
\hline \multirow{2}{*}{ GRADE } & \multicolumn{2}{|c|}{ BITTER LEAF } & \multicolumn{2}{c|}{ SCENT LEAF } \\
\cline { 2 - 5 } & Unwashed (\%) & Washed (\%) & Unwashed (\%) & Washed (\%) \\
\hline Extremely liked & 57 & 57.1 & 57 & 42.8 \\
\hline Moderately liked & 43 & 28.6 & 43 & 28.6 \\
\hline Liked & - & 14.3 & - & 28.6 \\
\hline Fair & - & - & - & - \\
\hline Bad & - & - & - & - \\
\hline Total & 100 & 100 & 100 & 100 \\
\hline
\end{tabular}

Table 4. Palatability of bitter leaf and scent leaf extracts preserved catfish (Clarias gariepinus) pepper soup.

\begin{tabular}{|c|c|c|c|c|}
\hline \multirow{2}{*}{ GRADE } & \multicolumn{2}{|c|}{ BITTER LEAF } & \multicolumn{2}{c|}{ SCENT LEAF } \\
\cline { 2 - 5 } & Unwashed (\%) & Washed (\%) & Unwashed (\%) & Washed (\%) \\
\hline Extremely liked & 42.8 & 28.6 & 14.23 & - \\
\hline Moderately liked & 28.6 & 71.4 & 42.85 & 14.28 \\
\hline Liked & 28.6 & - & 28.6 & 28.57 \\
\hline Fair & - & - & 14.28 & 14.28 \\
\hline Bad & - & - & - & 14.28 \\
\hline Total & 100 & 100 & 100 & 100 \\
\hline
\end{tabular}

Table 5. Palatability of bitter leaf and scent leaf extracts preserved smoked catfish (Clarias gariepinus).

\begin{tabular}{|c|c|c|c|c|}
\hline \multirow{2}{*}{ GRADE } & \multicolumn{2}{|c|}{ BITTER LEAF } & \multicolumn{2}{c|}{ SCENT LEAF } \\
\cline { 2 - 5 } & Unwashed (\%) & Washed (\%) & Unwashed (\%) & Washed (\%) \\
\hline Extremely liked & 43 & 28.6 & - & - \\
\hline Moderately liked & 57 & 28.6 & 14.3 & - \\
\hline Liked & - & 28.6 & 57 & 28.6 \\
\hline Fair & - & 14.3 & 28.6 & 71.4 \\
\hline Bad & - & - & - & - \\
\hline Total & 100 & 100 & 100 & 100 \\
\hline
\end{tabular}

(washed and unwashed) were unable to match their bitter leaf counterparts in terms of flavour, taste and appearance. The major complaint was that the scent leaf flavour was not pronounced in them. It was therefore suggested that the scent leaf not be washed to make the taste more pronounced and the concentration highly increased while soaking time in extract be increased. The smoking temperature was also advised to be improved upon for a better product to avoid too much fish-smoke contact. It can thus be concluded that catfish, Clarias gariepinus preserved with ethanolic extracts of bitter leaf and scent leaf is of good quality (in terms of taste and appearance) which can be greatly improved upon. It was also discovered from this work that fish products (smoked and pepper soup) preserved with extracts of unwashed bitter leaf is an acceptable product for the market because consumers will readily go for it when placed on sale. In view of this, fish mongers who deal in smoked fish could preserve their unsold fish by coating them with unwashed bitter leaf extract. Fresh fish could be soaked in bitter leaf extract before being prepared into pepper soup for sale because of the bitter flavour that is medicinal and helpful in the treatment of diseases like diabetes and fever 
reduction [7]. Unwashed scent leaf extract could also be used at high concentration to preserve fresh fish meant for smoking and pepper soup.

\section{References}

[1]. Azu NC, Onyeagba RA. Antimicrobial properties of extracts of Allium cepa (Onions) and Zingiber officinale (Ginger) on Escherichia coli, Salmonella typhi, and Bacillus subtilis. The Internet Journal of Tropical Medicine. 2007; 3(2):8.

[2]. Ephraim RN. Antimicrobial properties of extracts of Carica papaya, Citrus paradisa and Piper guineese on Microorganisms associated with catfish, Clarias gariepinus spoilage (Doctoral dissertation, M. Sc. Dissertation). 2010; 1-36.

[3]. Eyo AA. Fish processing technology in the tropics. National Institute for Freshwater Fisheries Research (NIFFR); 2001

[4]. Ezekwesili CN, Obiora KA, Ugwu OP. Evaluation of Anti-Diarrhoeal Prop- erty of Crude Aqueous Extract of Ocimum gratissimum L.(Labiatae) In Rats. Biokemistri. 2004; 16(2):121-131.

[5]. Friedman MI, Stricker EM. The Physiological Psychology of Hunger: A Physiological Perspective. Phychol Rev. 1976; 83(6): 409-31. PMID 1005583.

[6]. Ijeh II, Njoku OU, Ekenza EC. Medicinal evaluation of Xylopia aethiopica and Ocimum gratissimum. Journal of Medicinal and Aromatic Plant Sciences. 2004; 26: 44-7.

[7]. Okoli RI, Aigbe O, Ohaju-Obodo JO, Mensah JK. Medicinal herbs used for managing some common ailments among Esan people of Edo State, Nigeria. Pakistan Journal of Nutrition. 2007; 6(5):490-6.

[8]. Poste LM, Mackie DA, Butler G, Larmond E. Laboratory methods for sensory analysis of food, 2. Journal of the Japanese Society for Food Science and Technology (Japan). Research Branch Agriculture Canada Publication 1864/E. 2001.

[9]. Sherratt TN, Wilkinson DM, Bain RS. Why fruits rot, seeds mold and meat spoils: a reappraisal. Ecological Modelling. 2006 Feb 25; 192(3-4):618-26. 